\title{
SPECTROPHOTOMETRIC METHOD FOR ANTIOXIDANT ACTIVITY TEST AND TOTAL PHENOLIC DETERMINATION OF RED DRAGON FRUIT LEAVES AND WHITE DRAGON FRUIT LEAVES
}

\author{
Nerdy Nerdy ${ }^{1, *}$ and Kesaktian Manurung ${ }^{2}$ \\ ${ }^{1}$ Department of Pharmacy, Academy of Pharmacy Yayasan Tenaga Pembangunan Arjuna, \\ Pintubosi, Laguboti, Toba Samosir, Sumatera Utara, 22381, Indonesia \\ ${ }^{2}$ Department of Pharmacy, Faculty of Pharmacy and Health Sciences, University of Sari Mutiara \\ Indonesia, Dwi Kora, Medan Helvetia, Medan, Sumatera Utara, 20124, Indonesia \\ *E-mail: nerdy190690@gmail.com
}

\begin{abstract}
Dragon fruit is one of the fruits cultivated in the tropics. The fruit flesh of the dragon fruit has been widely consumed, and the fruit peel of the dragon fruit has also been extensively utilized. But the leaves of the dragon fruit have not been utilized and tend to be waste in agriculture. This study aims to utilize waste dragon fruit leaves with the test of antioxidant activity and the determination of total phenolic of red dragon fruit leaves extract and white dragon fruit leaves extract by spectrophotometric method. Methods performed for antioxidant activity test by 1,1diphenyl-2-picrylhydrazyl (DPPH) with ascorbic acid as the comparator and total phenolic determination by FolinCiocalteu (FC) with gallic acid as the comparator. Measurements were done with a spectrophotometer. Antioxidant activity test results of red dragon fruit leaves extract and white dragon fruit leaves extract obtained scavenging concentration $50 \%\left(\mathrm{SC}_{50}\right) 135.00 \mu \mathrm{g} / \mathrm{mL}$ and $142.47 \mu \mathrm{g} / \mathrm{mL}$. Total phenolic determination results of red dragon fruit leaves extract and white dragon fruit leaves extract obtained value $756.75 \mathrm{mg} / \mathrm{g}$ and $707.07 \mathrm{mg} / \mathrm{g}$. Both red dragon fruit leaves extract and white dragon fruit leaves extract to have moderate antioxidant activity.

Keywords: Antioxidant Activity, Total Phenolic, Red Dragon Fruit, White Dragon Fruit, Spectrophotometric
\end{abstract}

(c) RASĀYAN. All rights reserved

\section{INTRODUCTION}

Dragon fruit or Pitaya is a plant that grows in the tropics, belongs to Cactaceae family and Hylocereus genus ${ }^{1}$. Indonesia is a tropical country with the cultivation of two types of dragon fruit, namely white dragon fruit Hylocereus polyrhizus with characteristics red peel \& red flesh and Hylocereus undatus with characteristic red peel and white flesh. Differences between two types of dragon fruit are found in the flesh, so Hylocereus polyrhizus often referred to as red dragon fruit and Hylocereus undatus often referred to as white dragon fruit ${ }^{2}$. Figure-1 shows the different flesh color between red dragon fruit and white dragon fruit.

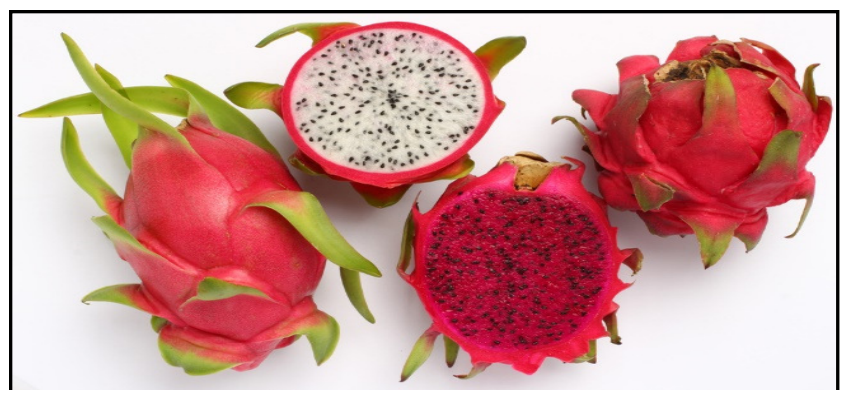

Fig.-1: Different Flesh Color between Red Dragon Fruit and White Dragon Fruit

Rasayan J. Chem., 11(3), 1183-1192(2018)

http://dx.doi.org/10.31788/RJC.2018.1134018

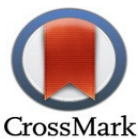


The dragon fruit flesh has several activities as an antioxidant ${ }^{3,4}$, anticancer ${ }^{5}$, antidiabetic ${ }^{6,7}$, antihypercholesterolemic ${ }^{8}$, and hepatoprotective. ${ }^{9}$ The dragon fruit peel has several activities as an antioxidant $^{3}$, and antibacterial. ${ }^{10,11}$ High nutritional contents of the dragon fruit cause the dragon fruit to be consumed. Nutritional contents of dragon fruit were the carbohydrate, protein, fat, crude fiber, ascorbic acid $^{12}$. Dragon fruit leaves are agricultural waste products. In this study, the researchers will do antioxidant activity test and total phenolic determination of dragon fruit leaves. It is expected that dragon fruit leaves have good antioxidant activity and high total phenolics so that the agricultural waste can be utilized optimally and has a high selling value.

\section{Tools and Materials}

\section{EXPERIMENTAL}

The tools used in this research were cutter (Deli), drying cabinet (Alumex), blender (Philips), balance (Sartorius), analytical balance (Sartorius), filter paper (Whatman), dropper (Iwaki), evaporating dish (Iwaki), maceration vessel (Iwaki), beaker glass (Iwaki), measuring glass (Iwaki), volumetric flask (Iwaki), test tube (Iwaki), hot plate stirrer (Thermo), water bath (Memmert), incubator (Memmert), rotary evaporator (Buchi), thermometer (Lutron), test sieve 10 (Retsch), stopwatch (Casio), spectrophotometer (Shimadzu).

The materials used in this research were white dragon fruit leaves, red dragon fruit leaves, distilled water (Brataco), methanol (E-Merck), sodium hydroxide (E-Merck), mercuric chloride (E-Merck), potassium iodide (E-Merck), tartaric acid (E-Merck), iodine (E-Merck), ammonia (E-Merck), amyl alcohol (EMerck), diethyl ether (E-Merck), acetic acid anhydride (E-Merck), sulfuric acid (E-Merck), hydrochloric acid (E-Merck), iron (III) chloride (E-Merck), lead (II) acetate (E-Merck), isopropanol (E-Merck), chloroform (E-Merck), ethanol (E-Merck), alpha naphtol (E-Merck), gallic acid (Sigma Aldrich), ascorbic acid (Sigma Aldrich), Folin-Ciocalteu (E-Merck), 2,2-Diphenyl-1-Picrylhydrazyl (Sigma Aldrich).

\section{Preparation of DPPH Stock Solution $0.5 \mathrm{mM}$}

$10 \mathrm{mg}$ of DPPH (molecular weight 394.32) was weighed, inserted into a $50.0 \mathrm{~mL}$ volumetric flask, added $30.0 \mathrm{~mL}$ methanol, shaken until dissolved, diluted with methanol to the marked line, and shaken homogeneously (obtained DPPH stock solution with concentration $0.5 \mathrm{mM}$ or $200 \mu \mathrm{g} / \mathrm{mL}$ ).

\section{Preparation of Gallic Acid Stock Solution $1000 \mu \mathrm{g} / \mathrm{mL}$}

$10 \mathrm{mg}$ of gallic acid was weighed, inserted into a $10.0 \mathrm{~mL}$ volumetric flask, added $6.0 \mathrm{~mL}$ methanol, shaken until dissolved, diluted with methanol to the marked line, and shaken homogeneously (obtained gallic acid stock solution with concentration $1000 \mu \mathrm{g} / \mathrm{mL}$ ).

\section{Preparation of Sodium Carbonate Solution $20 \% \mathrm{~m} / \mathrm{v}$}

$10 \mathrm{~g}$ of sodium carbonate was weighed, inserted into a $50.0 \mathrm{~mL}$ volumetric flask, added $30.0 \mathrm{~mL}$ water, shaken until dissolved, diluted with water to the marked line, and shaken homogeneously (obtained sodium carbonate solution with concentration $20 \% \mathrm{~m} / \mathrm{v}$ ).

\section{Preparation of Extract}

This research uses red dragon fruit leaves, white dragon fruit leaves as the samples obtained from Gundaling, Berastagi, Karo, Sumatera Utara, 22152, Indonesia. Samples were sorted, washed, drained, cut, dried, powdered, and sieved. The extraction process was based on a modification of Malik and Ahmad $^{13}$ maceration method. One kilogram of dried leaves powder was weighed, inserted into a maceration vessel, added $10 \mathrm{~L}$ methanol, stirred daily for 5 days $(5 \times 24$ hours $)$, and filtered the mixture. The residue was added $5 \mathrm{~L}$ methanol, stirred daily for 3 days $(3 \times 24$ hours), and filtered the mixture. The aqueous extract was evaporated with a rotary evaporator until a viscous extract was obtained. The extracts obtained were tested for phytochemical content of alkaloids, flavonoids, tannins, saponins, glycosides, steroids, and terpenoids ${ }^{13}$.

\section{Determination of DPPH Maximum Wavelength and Operating Time}

$2.5 \mathrm{~mL}$ of DPPH stock solution was taken, inserted into a $25.0 \mathrm{~mL}$ volumetric, diluted with methanol to the marked line, and shaken homogeneously (obtained solution with DPPH concentration $20 \mu \mathrm{g} / \mathrm{mL}$ ). The 
solution absorbance was measured at a wavelength of $400 \mathrm{~nm}-800 \mathrm{~nm}$, and obtained the maximum wavelength. Subsequently, the solution was measured at maximum wavelength every 1 minute, observed the time required for the solution to produce a stable absorbance, and obtained the operating time.

\section{Test of Antioxidant Activity}

Test of antioxidant activity was based on a modification of Desmiaty et al. ${ }^{14}$ research method. The procedure is divided into a procedure for positive control, the procedure for positive control, and procedure for sample ${ }^{14}$.

Procedure for Negative Control: $5.0 \mathrm{~mL}$ of DPPH stock solution was taken, inserted into a $25 \mathrm{~mL}$ volumetric flask, diluted with methanol to the marked line, and shaken homogeneously (obtained solution with DPPH concentration $40 \mu \mathrm{g} / \mathrm{mL}$ ). The solution was left until the operating time, measured the absorbance at a maximum wavelength, and obtained the absorbance.

Procedure for Positive Control: $12.5 \mathrm{mg}$ of ascorbic acid was weighed, inserted into a $100.0 \mathrm{~mL}$ volumetric flask, added $60.0 \mathrm{~mL}$ methanol, shaken until dissolved, diluted with methanol to the marked line, and shaken homogeneously (obtained an ascorbic acid stock solution with concentration 125 $\mu \mathrm{g} / \mathrm{mL}$ ). $1.0 \mathrm{~mL}, 2.0 \mathrm{~mL}, 3.0 \mathrm{~mL}, 4.0 \mathrm{~mL}$, and $5.0 \mathrm{~mL}$ of ascorbic acid stock solution was taken, inserted into a separate $25.0 \mathrm{~mL}$ volumetric, added $5.0 \mathrm{~mL} \mathrm{DPPH}$ stock Solution, diluted with methanol to the marked line, and shaken homogeneously (obtained solution with DPPH concentration $40 \mu \mathrm{g} / \mathrm{mL}$ and ascorbic acid concentration $5 \mu \mathrm{g} / \mathrm{mL}, 10 \mu \mathrm{g} / \mathrm{mL}, 15 \mu \mathrm{g} / \mathrm{mL}, 20 \mu \mathrm{g} / \mathrm{mL}$, and $25 \mu \mathrm{g} / \mathrm{mL}$ ). Each solution was left until the operating time, measured the absorbance at a maximum wavelength, and obtained the absorbance.

Procedure for Sample: $125 \mathrm{mg}$ of the extract was weighed, inserted into a $100.0 \mathrm{~mL}$ volumetric flask, added $60.0 \mathrm{~mL}$ methanol, shaken until dissolved, diluted with methanol to the marked line, and shaken homogeneously (obtained extract stock solution with concentration $1250 \mu \mathrm{g} / \mathrm{mL}$ ). $1.0 \mathrm{~mL}, 2.0 \mathrm{~mL}, 3.0$ $\mathrm{mL}, 4.0 \mathrm{~mL}$, and $5.0 \mathrm{~mL}$ of extract stock solution was taken, inserted into a separate $25.0 \mathrm{~mL}$ volumetric, added 5.0 mL DPPH stock solution, diluted with methanol to the marked line, and shaken homogeneously (obtained solution with DPPH concentration $40 \mu \mathrm{g} / \mathrm{mL}$ and extract concentration $50 \mu \mathrm{g} / \mathrm{mL}, 100 \mu \mathrm{g} / \mathrm{mL}$, $150 \mu \mathrm{g} / \mathrm{mL}, 200 \mu \mathrm{g} / \mathrm{mL}$, and $250 \mu \mathrm{g} / \mathrm{mL}$ ). Each solution was left until the operating time, measured the absorbance at a maximum wavelength, and obtained the absorbance.

The absorbance of negative control, positive control, and samples obtained, then performed calculations of free radical scavenging activity by subtraction of control absorbance with treatment absorbance, and division with treatment absorbance. The result, followed by calculation of the regression equation $(\mathrm{y}=\mathrm{ax}$ $+\mathrm{b})$ with sample concentration $(\mu \mathrm{g} / \mathrm{ml})$ as the axis $(\mathrm{x})$ and free radical scavenging activity $(\%)$ as the ordinate (y). Ended with the calculation of $\mathrm{SC}_{50}$ value (Scavenging Concentration $50 \%$ ), the value describes the concentration of compounds that can scavenge of $50 \%$ free radical. Each concentration of each treatment was replicated 6 times.

\section{Determination of Gallic Acid with FC Maximum Wavelength and Operating Time}

$0.4 \mathrm{~mL}$ of the gallic acid stock solution was taken, inserted into a $10.0 \mathrm{~mL}$ volumetric, diluted with methanol to the marked line, and shaken homogeneously (obtained gallic acid solution with concentration $40 \mu \mathrm{g} / \mathrm{mL}$ ). $0.5 \mathrm{~mL}$ of gallic acid solution was taken, inserted into a $10.0 \mathrm{~mL}$ volumetric flask, added 7.5 $\mathrm{mL}$ water, added $0.5 \mathrm{~mL}$ of FC solution, homogenized with vortex for 1 min, diluted with sodium carbonate solution to the marked line, and shaken homogeneously. The solution absorbance was measured at a wavelength of $400 \mathrm{~nm}-800 \mathrm{~nm}$, and obtained the maximum wavelength. Subsequently, the solution was measured at maximum wavelength every 1 minute, observed the time required for the solution to produce a stable absorbance, and obtained the operating time.

\section{Determination of Total Phenolic}

Determination of total phenolic was based on a modification of Agbo et al. ${ }^{15}$ research method. The procedure is divided into a procedure for regression equation and procedure for sample ${ }^{15}$.

Procedure for Regression Equation: $0.2 \mathrm{~mL}, 0.3 \mathrm{~mL}, 0.4 \mathrm{~mL}, 0.5 \mathrm{~mL}, 0.6 \mathrm{~mL}, 0.7 \mathrm{~mL}$, and $0.8 \mathrm{~mL}$ of gallic acid stock solution was taken, inserted into a $10.0 \mathrm{~mL}$ volumetric, diluted with methanol to the 
marked line, and shaken homogeneously (obtained solution with gallic acid concentration $20 \mu \mathrm{g} / \mathrm{mL}, 30$ $\mu \mathrm{g} / \mathrm{mL}, 40 \mu \mathrm{g} / \mathrm{mL}, 50 \mu \mathrm{g} / \mathrm{mL}, 60 \mu \mathrm{g} / \mathrm{mL}, 70 \mu \mathrm{g} / \mathrm{mL}$, and $80 \mu \mathrm{g} / \mathrm{mL}) .0 .5 \mathrm{~mL}$ of each gallic acid solution was taken, inserted into a $10.0 \mathrm{~mL}$ volumetric flask, added $7.5 \mathrm{~mL}$ water, added $0.5 \mathrm{~mL}$ of FC solution, homogenized with vortex for $1 \mathrm{~min}$, diluted with sodium carbonate solution to the marked line, and shaken homogeneously. Each solution was left until the operating time, measured the absorbance at a maximum wavelength, and obtained the absorbance. The result, followed by calculation of the regression equation $(\mathrm{y}=\mathrm{ax}+\mathrm{b})$ with sample concentration $(\mu \mathrm{g} / \mathrm{ml})$ as the axis (x) and free absorbance (AU) as the ordinate $(\mathrm{y})$. Each concentration was replicated 6 times.

Procedure for Sample: $10 \mathrm{mg}$ of the extract was weighed, inserted into a $10.0 \mathrm{~mL}$ volumetric flask, added $6.0 \mathrm{~mL}$ methanol, shaken until dissolved, diluted with methanol to the marked line, and shaken homogeneously (obtained extract stock solution with concentration $1000 \mu \mathrm{g} / \mathrm{mL}$ ). $0.5 \mathrm{~mL}$ of extract stock solution was taken, inserted into a $10.0 \mathrm{~mL}$ volumetric, diluted with methanol to the marked line, and shaken homogeneously (obtained solution with extract concentration $50 \mu \mathrm{g} / \mathrm{mL}$ ). $0.5 \mathrm{~mL}$ of extract solution was taken, inserted into a $10.0 \mathrm{~mL}$ volumetric flask, added $7.5 \mathrm{~mL}$ water, added $0.5 \mathrm{~mL}$ of FC solution, homogenized with vortex for $1 \mathrm{~min}$, diluted with sodium carbonate solution to the marked line, and shaken homogeneously. The solution was left until the operating time, measured the absorbance at a maximum wavelength, and obtained the absorbance. The phenol concentration in the sample was calculated from the regression equation and the content of the phenol compound followed by calculations expressed as mg of gallic acid in $\mathrm{g}$ of sample. Each treatment was replicated 6 times.

\section{Extract}

\section{RESULTS AND DISCUSSION}

Extraction of red dragon fruit leaves and white dragon fruit leaves by a maceration method with methanol as the solvent. $1000 \mathrm{~g}$ of red dragon fruit leaves dried powder obtained $139.2 \mathrm{~g}$ (yield percentage 13.92\%) methanol extract with dark green color. $1000 \mathrm{~g}$ of red dragon fruit leaves dried powder obtained $128.1 \mathrm{~g}$ (yield percentage 12.81\%) methanol extract with dark green color.Results of the phytochemical content test for red dragon fruit leaves extract and white dragon fruit leaves extract was shown in Table-1.

Table-1: Results of the phytochemical content test for red dragon fruit leaves extract and white dragon fruit leaves

\begin{tabular}{c|c|c|c}
\hline Number & Compounds & $\begin{array}{c}\text { Red Dragon Fruit } \\
\text { Leaves Extract }\end{array}$ & $\begin{array}{c}\text { White Dragon Fruit } \\
\text { Leaves Extract }\end{array}$ \\
\hline 1 & Alkaloids & + & + \\
\hline 2 & Flavonoids & + & + \\
\hline 3 & Tannins & + & + \\
\hline 4 & Saponins & + & + \\
\hline 5 & Glycosides & + & + \\
\hline 6 & Steroids & + & + \\
\hline 7 & Terpenoids & + & +
\end{tabular}

Phytochemical content in red dragon fruit leaves extract similar to white dragon fruit leaves extract. Both extracts contain all types of phytochemical content. Both of the extract contains the phenolic compound. The presence of a phenolic compound in the extract was indicated by the antioxidant activity of the extract ${ }^{16}$. The phytochemical compounds of alkaloids, flavonoids, tannins, saponins, glycosides, steroids, and terpenoids are in the simple form or complex form of phenolic compound ${ }^{17}$.

\section{DPPH Maximum Wavelength and Operating Time}

Antioxidant activity test by DPPH method is fast and uncomplicated, it requires only an ultraviolet-visible spectrophotometer to perform the analysis, which explains its widespread use in screening antioxidant activity ${ }^{18}$. Antioxidant activity test by DPPH method is done by measurement using spectrophotometer which begins with the determination of maximum wavelength. Absorption curve of DPPH solution 
(violet color with concentration of $40 \mu \mathrm{g} / \mathrm{mL}$ ) obtained from visible spectrophotometric measurement can be seen in Fig.-2.

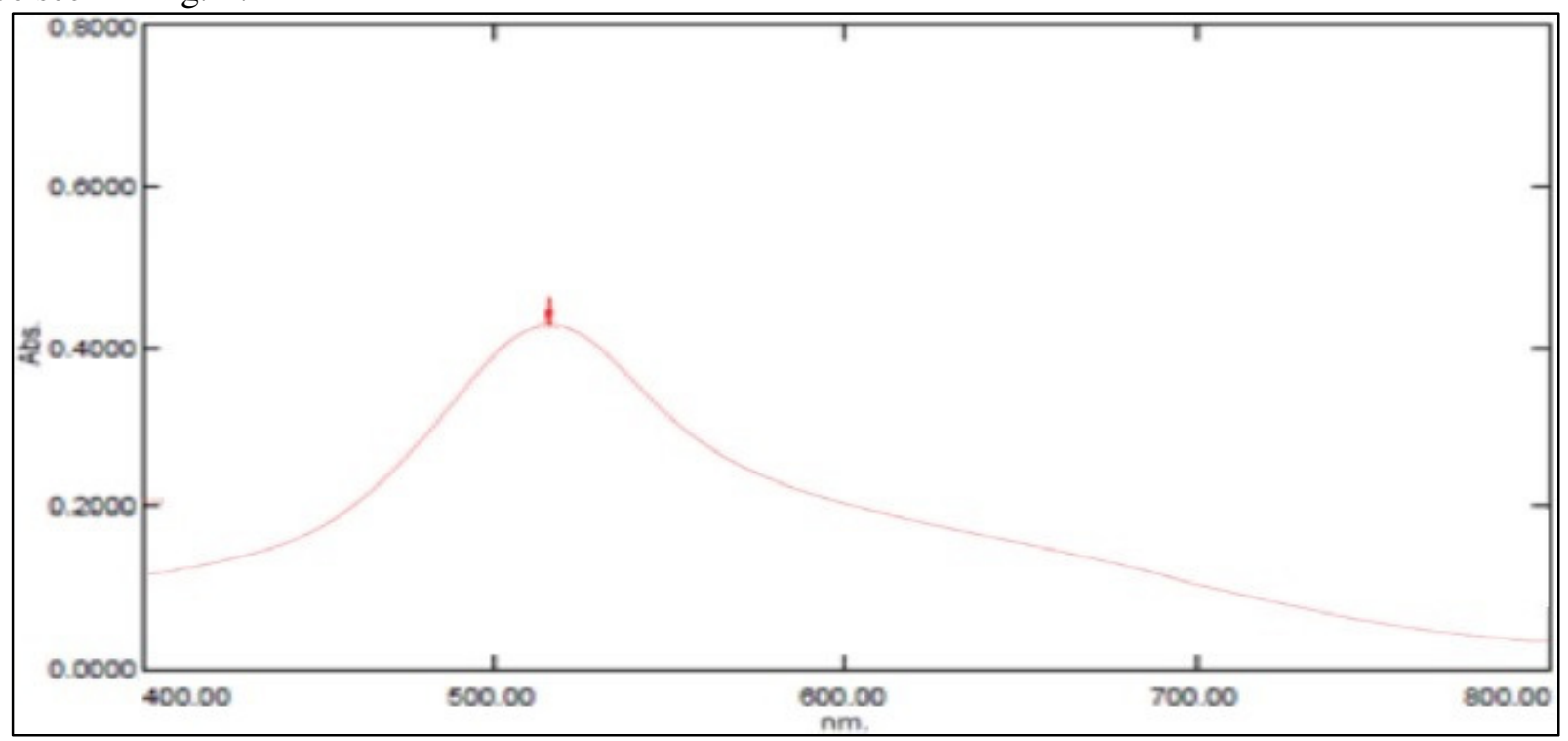

Fig.-2: Absorption curve of DPPH solution (violet color with a concentration of $40 \mu \mathrm{g} / \mathrm{mL}$ ) obtained from the visible spectrophotometric measurement

Maximum wavelength obtained from DPPH solution was $515 \mathrm{~nm}$. This result also corresponds to the literature that states the maximum wavelength for DPPH solution is $515 \mathrm{~nm}^{19}$. For colored solutions, the operating times are measured to determine the exact measurement time (providing stable absorbance). The result of the determination of operating time obtained that the exact measurement time is 28 minutes to 33 minutes. This result is also in accordance with the antioxidant activity test by DPPH method with about 30 minutes solution left in dark container before the measurement ${ }^{20}$.

\section{Determination of Antioxidant Activity}

Test of antioxidant activity from red dragon fruit leaves extract and white dragon fruit leaves extract by DPPH method. Data of antioxidant activity test of ascorbic acid, red dragon fruit leaves extract, and white dragon fruit leaves extract can be seen in Table-2. Results of the regression line and regression equation of different concentration of ascorbic acid, red dragon fruit leaves extract, and white dragon fruit leaves extract with DPPH solution in antioxidant activity test can be seen in Fig.-3, Fig.-4, and Fig.-5.

Table-2: Data of antioxidant activity test of ascorbic acid, red dragon fruit leaves extract, and white dragon fruit leaves extract

\begin{tabular}{|c|c|c|c|c|c|}
\hline Number & Sample & $\begin{array}{l}\text { Concentration } \\
(\mu \mathrm{g} / \mathrm{mL})\end{array}$ & $\begin{array}{c}\text { Average } \\
\text { Absorbance } \\
(\mathrm{AU})\end{array}$ & $\begin{array}{c}\text { Average } \\
\text { Scavenging } \\
\text { Activity }(\%)\end{array}$ & $\begin{array}{c}\text { Standard } \\
\text { Deviation }(\%)\end{array}$ \\
\hline 1 & Blank & 0.00 & 0.75146 & 0.00 & 2.13 \\
\hline 2 & \multirow{5}{*}{ Ascorbic Acid } & 5.00 & 0.62745 & 16.50 & 2.47 \\
\hline 3 & & 10.00 & 0.49974 & 33.50 & 2.81 \\
\hline 4 & & 15.00 & 0.37579 & 49.99 & 2.53 \\
\hline 5 & & 20.00 & 0.25140 & 66.55 & 2.02 \\
\hline 6 & & 25.00 & 0.12571 & 83.27 & 1.25 \\
\hline 7 & \multirow{5}{*}{$\begin{array}{l}\text { Red Dragon Fruit } \\
\text { Leaves Extract }\end{array}$} & 50.00 & 0.61272 & 18.46 & 2.03 \\
\hline 8 & & 100.00 & 0.47380 & 36.95 & 1.83 \\
\hline 9 & & 150.00 & 0.33473 & 55.46 & 1.71 \\
\hline 10 & & 200.00 & 0.19594 & 73.93 & 1.51 \\
\hline 11 & & 250.00 & 0.05413 & 92.80 & 0.67 \\
\hline
\end{tabular}


RASĀYAN $J$. Chem.

Vol. 11 | No. 3 |1183 - 1192 | July - September | 2018

\begin{tabular}{l|c|c|c|c|c}
\hline 12 & & & & \\
\hline \multirow{2}{*}{ White Dragon Fruit } & 50.00 & 0.61774 & 17.79 & 1.15 \\
\cline { 4 - 5 } & \multirow{2}{*}{ Leaves Extract } & 100.00 & 0.48123 & 35.96 & 1.05 \\
\cline { 3 - 5 } & & 200.00 & 0.35739 & 52.44 & 1.28 \\
\cline { 3 - 5 } & & 0.22030 & 70.68 & 2.44 \\
\hline 15 & 250.00 & 0.09859 & 86.88 & 1.31 \\
\hline 16 & & \multicolumn{4}{|c}{} \\
\hline
\end{tabular}

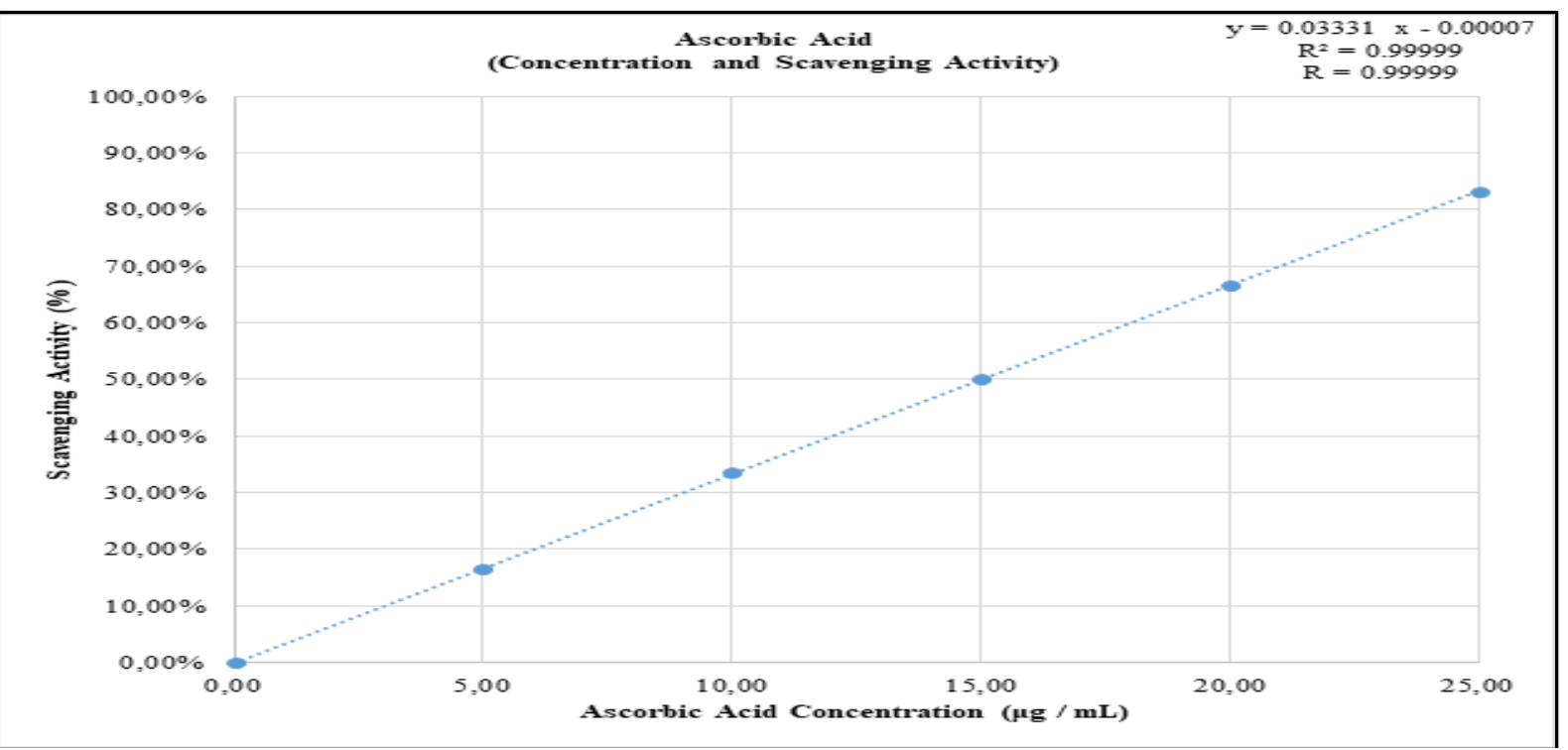

Fig.-3: Results of the regression line and regression equation of different concentration of ascorbic acid with DPPH solution in the antioxidant activity test

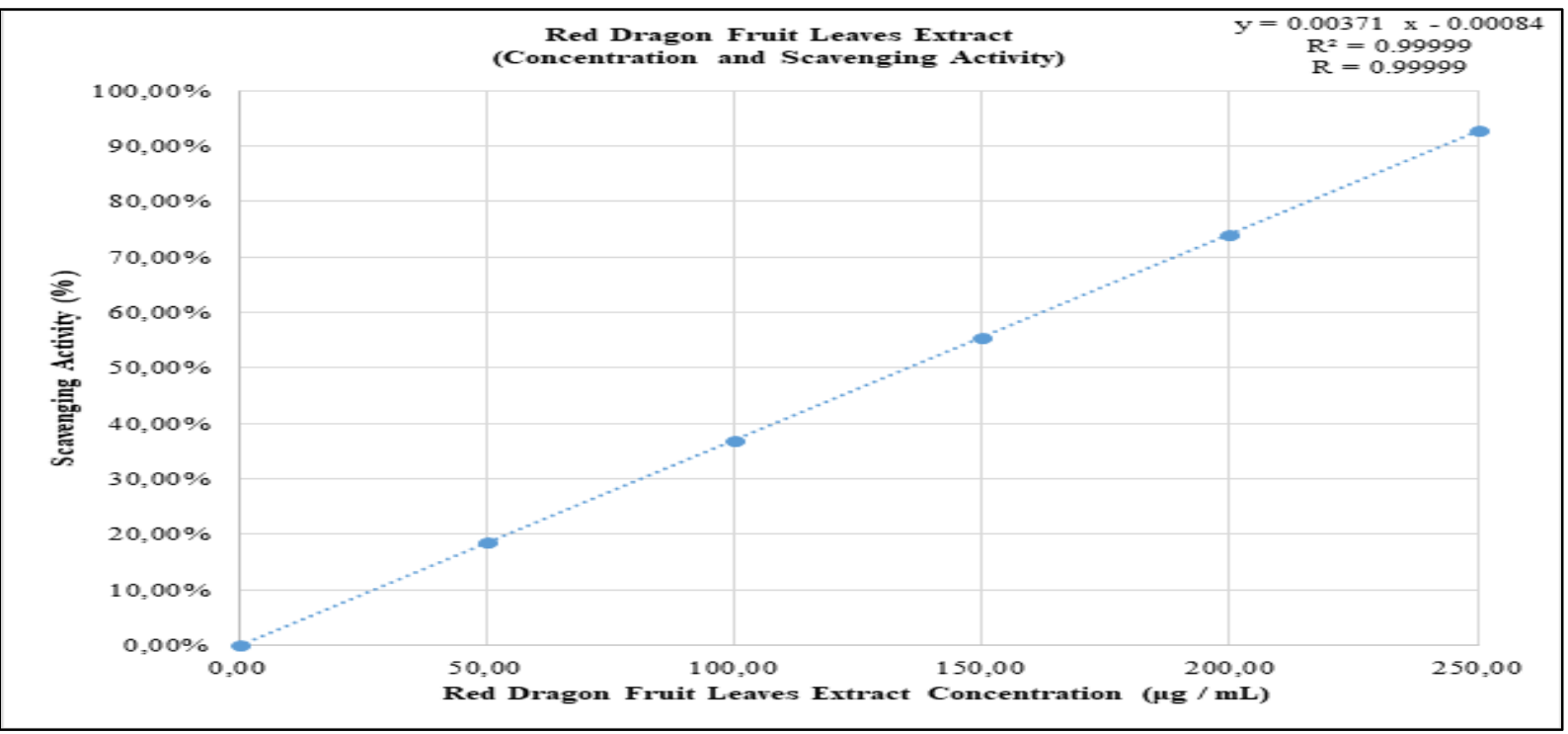

Fig.-4: Results of the regression line and regression equation of different concentration of red dragon fruit leaves extract with DPPH solution in the antioxidant activity test

The regression line plotted between concentration and scavenging activity obtained linear line. Regression equation obtained for ascorbic acid, red dragon fruit leaves extract, and white dragon fruit leaves extract $\mathrm{y}=0.03331 \mathrm{x}-0.00007, \mathrm{y}=0.00371 \mathrm{x}-0.00084$, and $\mathrm{y}=0.00348 \mathrm{x}+0.00421$. The determination coefficient $\left(\mathrm{R}^{2}\right)$ obtained for ascorbic acid, red dragon fruit leaves extract, and white dragon fruit leaves extract were 0.99999, 0.99999, and 0.99972. The correlation coefficient (R) obtained for ascorbic acid, red dragon fruit leaves extract, and white dragon fruit leaves extract were 0.99999, 0.99999, and 0.99986. Good correlation coefficient shows the correlation between concentration and 
scavenging activity. The higher the concentration the stronger the free radical scavenging activity. The determination coefficient $\left(\mathrm{R}^{2}\right)$ and correlation coefficient $(\mathrm{R})$ obtained meets the requirements of not less than 0.997 and not less than $0.998^{21}$.

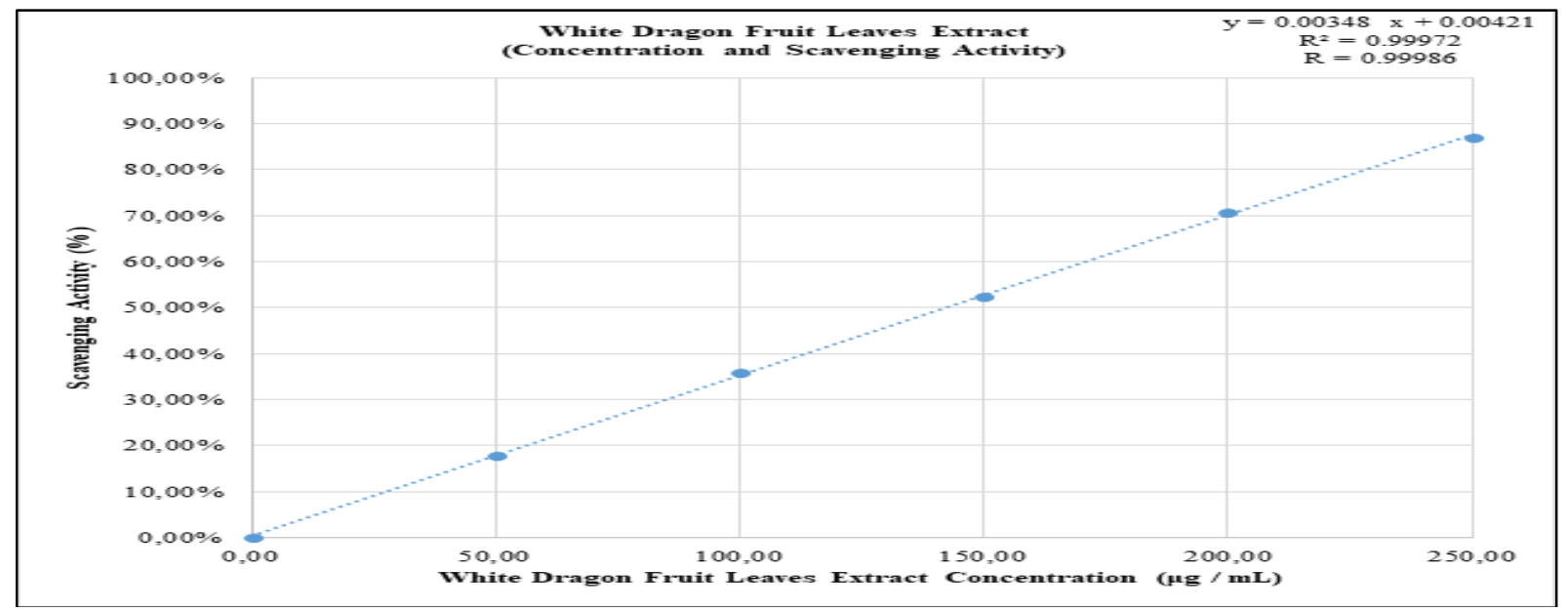

Fig.-5: Results of the regression line and regression equation of different concentration of white dragon fruit leaves extract with DPPH solution in the antioxidant activity test

The higher the concentration of compound or extract to scavenging the free radical, the lower the absorbance obtained from the measurement by spectrophotometric method ${ }^{22}$. To find out the value of $\mathrm{SC}_{50}$ concentration (the $\mathrm{x}$-axis), substituted $50 \%(0.5)$ to the free radical scavenging activity (the $\mathrm{y}$ ordinate). The value of the concentration (x) obtained was $\mathrm{SC}_{50}$ for ascorbic acid, red dragon fruit leaves extract, and white dragon fruit leaves extract was $15.01 \mu \mathrm{g} / \mathrm{mL}, 135.00 \mu \mathrm{g} / \mathrm{mL}$, and $142.47 \mu \mathrm{g} / \mathrm{mL}$. According to literature $\mathrm{SC}_{50}$ less than $50 \mu \mathrm{g} / \mathrm{mL}$ indicate highly active, $51 \mu \mathrm{g} / \mathrm{mL}-100 \mu \mathrm{g} / \mathrm{mL}$ indicate active, $101 \mu \mathrm{g} / \mathrm{mL}$ - $250 \mu \mathrm{g} / \mathrm{mL}$ indicate moderate, $251 \mu \mathrm{g} / \mathrm{mL}$ - $500 \mu \mathrm{g} / \mathrm{mL}$ weak, and more than 500 $\mu \mathrm{g} / \mathrm{mL}$ indicate inactive $\mathrm{e}^{23}$.

These results indicate that red dragon fruit leaves extract and white dragon fruit leaves extract to have moderate antioxidant activity, while ascorbic acid has highly active antioxidant activity. From this result, it is also known that the antioxidant activity of red dragon fruit leaves extract is higher than white dragon fruit leaves extract. The smaller value of $\mathrm{SC}_{50}$ will cause the higher antioxidant activity of a compound ${ }^{24}$. The higher antioxidant activity of red dragon fruit leaves extract than white dragon fruit leaves extract may be due to the more phenolic compound in red dragon fruit leaves extract than white dragon fruit leaves extract. The higher phenolic compound in the extract, then the higher antioxidant activity ${ }^{25}$. So the examination continues with the determination of total phenolics.

\section{Determination of Total Phenolic with FC Maximum Wavelength and Operating Time}

Total phenolic determination by the FC method is simple, it requires only an ultraviolet-visible spectrophotometer to perform the analysis, which explains its widespread use in screening total phenolic $^{26}$. Total phenolic determination by FC method is done by measurement using spectrophotometer which begins with the determination of maximum wavelength. The standard compound used to represent phenolic compound was gallic acid ${ }^{27}$. Absorption curve of gallic acid as the phenolic compound with FC solution (blue color with phenolic compound concentration $40 \mu \mathrm{g} / \mathrm{mL}$ ) obtained from visible spectrophotometric measurement can be seen in Fig.-6.

Maximum wavelength obtained from a phenolic compound with FC solution was $765 \mathrm{~nm}$. This result also corresponds to the literature that states the maximum wavelength for a phenolic compound with FC solution adalah $765 \mathrm{~nm}^{28}$. For colored solutions, the operating times are measured to determine the exact measurement time (providing stable absorbance). The result of the determination of operating time obtained that the exact measurement time is 33 minutes to 38 minutes. This result is also in accordance 
with the total phenolic determination by FC method with about 35 minutes solution left in dark container before the measurement ${ }^{29}$.

\section{Determination of Total Phenolic Content}

Results of the regression line and regression equation of different concentration of gallic acid as the phenolic compound with FC solution for total phenolic determination can be seen in Fig. -7 .

The regression line plotted between concentration and absorbance obtained linear line. Regression equation obtained for gallic acid as the phenolic compound with FC solution was $\mathrm{y}=0.01000 \mathrm{x}+$ 0.00006.The determination coefficient $\left(\mathrm{R}^{2}\right)$ obtained for gallic acid as the phenolic compound with FC solution was 0.99999 . The correlation coefficient $(\mathrm{R})$ obtained for gallic acid as the phenolic compound with FC solution was 0.99999 . Good correlation coefficient shows the correlation between concentration and absorbance. The higher the concentration the higher the absorbance. The determination coefficient $\left(\mathrm{R}^{2}\right)$ and correlation coefficient $(\mathrm{R})$ obtained meets the requirements of not less than 0.997 and not less than $0.998^{21}$. Data of total phenolic determination of red dragon fruit leaves extract and white dragon fruit leaves extract can be seen in Table-3.

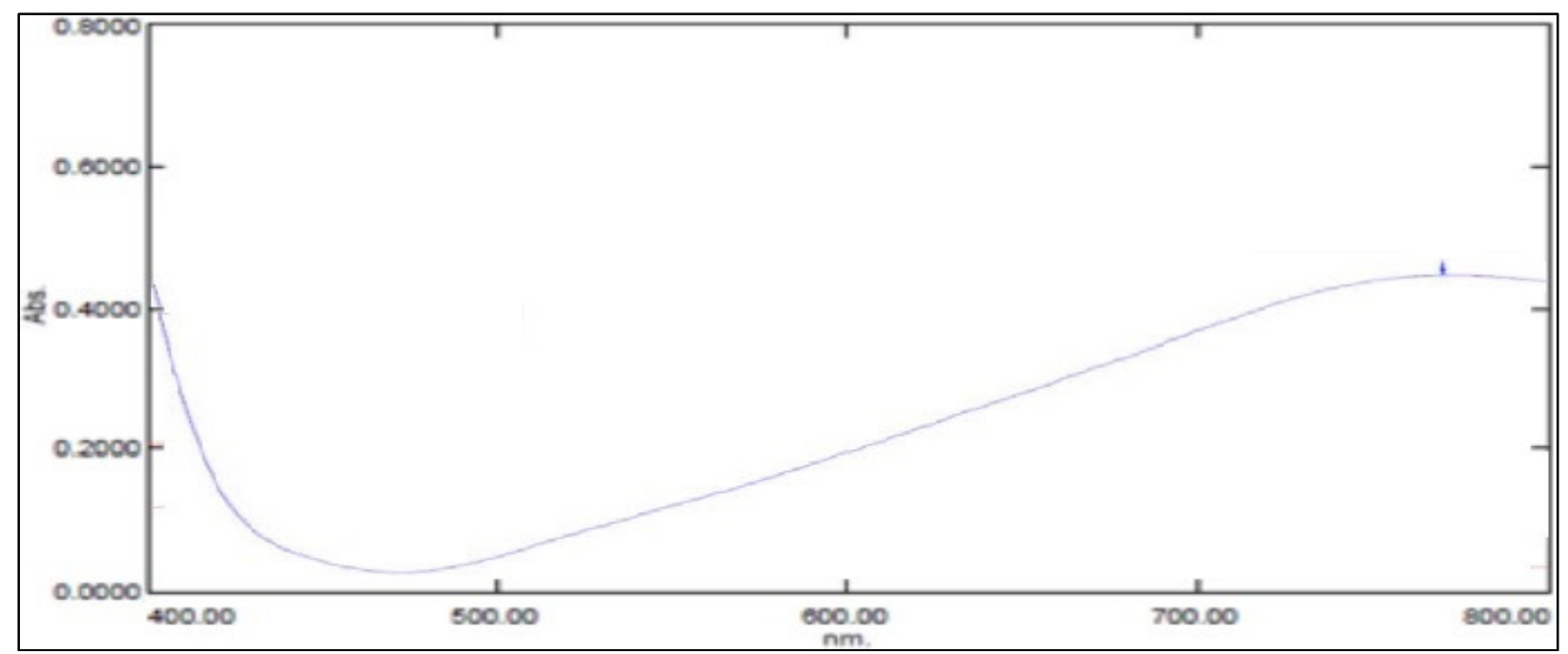

Fig.-6: Absorption curve of gallic acid as the phenolic compound with FC solution (blue color with phenolic compound concentration $40 \mu \mathrm{g} / \mathrm{mL}$ ) obtained from the visible spectrophotometric measurement

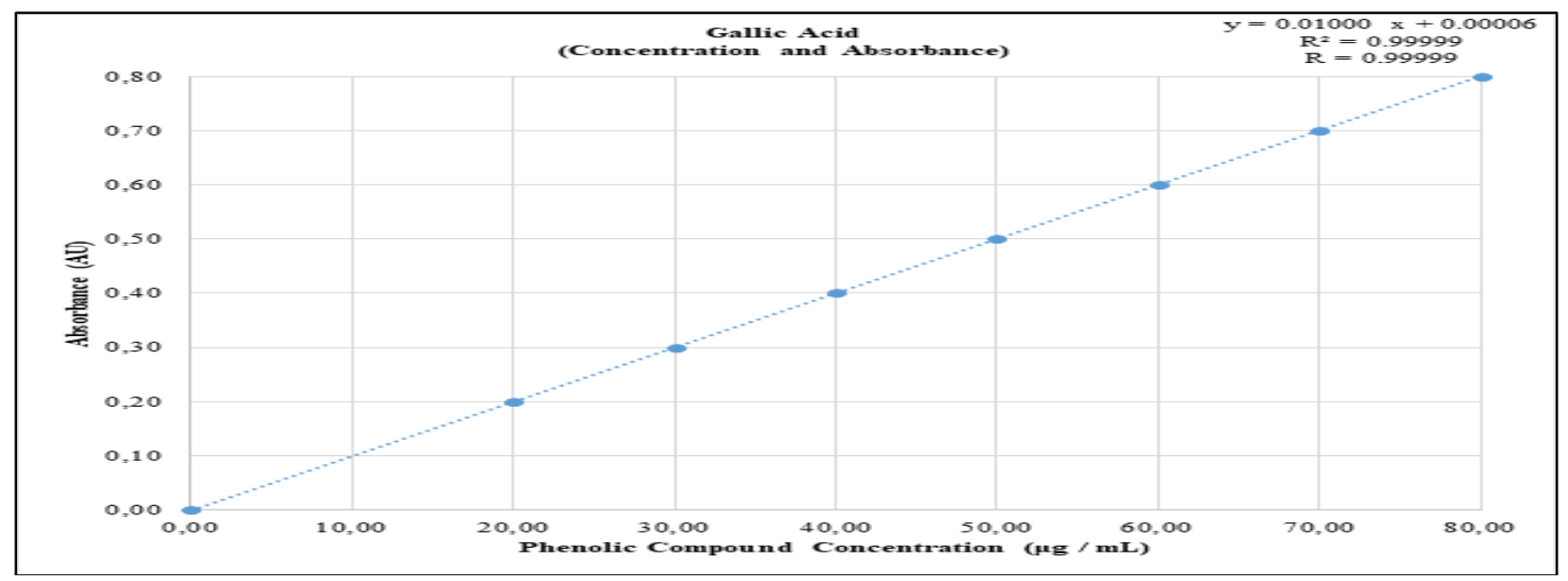

Fig.-7: Results of the regression line and regression equation of different concentration of gallic acid as the phenolic compound with FC solution for total phenolic determination

The phenolic compound contained in red dragon fruit leaves extract higher than red dragon fruit leaves extract. The total phenolic determination results for red dragon fruit leaves extract was $756.75 \mathrm{mg} / \mathrm{g}$ and 
for white dragon fruit leaves extract was $707.07 \mathrm{mg} / \mathrm{g}$. These results are in line with the results of the antioxidant activity test. Phenolic compounds have been characterized in plants, fruits, and vegetables as the prime sources of natural antioxidant $\mathrm{s}^{30}$. There is a correlation between the total phenolics and the antioxidant activity. The higher the phenolic compound contained in an extract will have higher antioxidant activity ${ }^{31,32}$.

Table-3: Data of total phenolic determination of red dragon fruit leaves extract and white dragon fruit leaves extract

\begin{tabular}{|c|c|c|c|c|}
\hline Number & Sample & $\begin{array}{c}\text { Absorbance } \\
(\mathrm{AU})\end{array}$ & $\begin{array}{c}\text { Concentration } \\
(\mu \mathrm{g} / \mathrm{mL})\end{array}$ & $\begin{array}{l}\text { Total Phenolic } \\
(\mathrm{mg} / \mathrm{g})\end{array}$ \\
\hline 1 & \multirow{6}{*}{$\begin{array}{l}\text { Red Dragon Fruit } \\
\text { Leaves Extract }\end{array}$} & 0.38182 & 38.17600 & 763.52 \\
\hline 2 & & 0.37525 & 37.51900 & 750.38 \\
\hline 3 & & 0.37721 & 37.71500 & 754.30 \\
\hline 4 & & 0.38281 & 38.27500 & 765.50 \\
\hline 5 & & 0.37427 & 37.42100 & 748.42 \\
\hline 6 & & 0.37925 & 37.91900 & 758.38 \\
\hline- & Average & 0.37844 & 37.83750 & 756.75 \\
\hline- & Standard Deviation & 0.00347 & 0.34715 & 6.94 \\
\hline 7 & \multirow{6}{*}{$\begin{array}{c}\text { White Dragon Fruit } \\
\text { Leaves Extract }\end{array}$} & 0.35067 & 35.06100 & 701.22 \\
\hline 8 & & 0.35612 & 35.60600 & 712.12 \\
\hline 9 & & 0.35219 & 35.21300 & 704.26 \\
\hline 10 & & 0.35431 & 35.42500 & 708.50 \\
\hline 11 & & 0.35315 & 35.30900 & 706.18 \\
\hline 12 & & 0.35513 & 35.50700 & 710.14 \\
\hline- & Average & 0.35360 & 35.35350 & 707.07 \\
\hline- & Standard Deviation & 0.00200 & 0.19985 & 4.00 \\
\hline
\end{tabular}

\section{CONCLUSION}

Both red dragon fruit leaves extract and white dragon fruit leaves extract to have moderate antioxidant activity. The antioxidant activity of red dragon fruit leaves is higher than the antioxidant activity of white dragon fruit leaves. This is because the total phenolic in red dragon fruit leaves is higher than total phenolic in white dragon fruit leaves.

\section{ACKNOWLEDGMENT}

The authors acknowledge the financial support by the Department of Pharmacy, Academy of Pharmacy Yayasan Tenaga Pembangunan Arjuna, Pintubosi, Laguboti, Toba Samosir, Sumatera Utara, 22381, Indonesia.

\section{REFERENCES}

1. S.T. De Freitas, and E.J. Mitcham, Scientia Agricola, 70(4), 257(2013).

2. S. Soeparjono, International Journal of Advances in Agricultural \& Environmental Engineering. 2(2), 79(2015), DOI: 10.15242/IJAAEE.ER1215049.

3. R. Nurliyana, I. Syed Zahir, K. Mustapha Suleiman, M.R. Aisyah, and K. Kamarul Rahim, International Food Research Journal, 17, 367(2010).

4. W.S. Choo, and W.K. Yong, Pelagia Research Library Advances in Applied Science Research, 2(3), 418(2011).

5. R. Dasaesamoh, W. Youravong, and S. Wichienchot,International Food Research Journal, 23(6), 2581(2016).

6. A. Omidizadeh, R.M.Yusof, S. Roohinejad, A. Ismail, M.Z.A.Bakar, and A.E.D.A Bekhitb, Royal Society of Chemistry Advances, 4, 62978(2014), DOI: 10.1039/c4ra10789f.

7. K. Sudha, D. Baskatan, D. Ramasamy, and M. Siddharth, International Journal of Agricultural Science and Research, 7(5), 451(2017).

8. S.R. Shafie, R.M. Yusuf, A. Rahmat, and A.M. Al-Saufreen, International Conference on Nutrition and Food Sciences, 39, 215(2012). 
9. A.M.T. Islam, M.A.U. Chowdhury, M.E. Uddin, M.M. Rahman, M.R. Habib, M.G.M. Uddin, and M.A. Rahman, European Journal of Medicinal Plants, 3(4), 500(2013).

10. M.M. Nurmahani, A. Osman, A.A. Hamid, F.M. Ghazali, and M.S.P. Dek, International Food Research Journal, 19(1), 77(2012).

11. J.G. Romero, K.G. Waing, and M.J. Valentino, International Journal of Biology, Pharmacy and Applied Sciences, 6(6), 1169(2017).

12. R.A. Jaafar,A.R.B.A.Rahman, N.Z.C. Mahmod, and R. Vasudevan, American Journal of Applied Sciences, 6(7), 1341(2009).

13. A. Malik, and R. Ahmad, International Journal of PharmTech Research, 7(2), 243(2015).

14. Y. Desmiaty, D. Rahmat, and H. Afifah, Research Journal of Pharmaceutical, Biological and Chemical Sciences, 8(1), 275(2017).

15. M.O. Agbo, P.F. Uzor, U.N. Akazie-Nneji, C.U. Eze-Odurukwe, U. B. Ogbatue, and E.C. Mbaoji, Dhaka University Journal of Pharmaceutical Sciences, 14(1), 1(2015), DOI: 10.3329/dujps.v14i1.23733.

16. V. Ramamurthy, and M. Sathiyadevi, Journal of Molecular Histology \& Medical Physiology, 2(1), 112(2017).

17. M. Saxena, J. Saxena, R.Nema, D. Singh, and A. Gupta, Journal of Pharmacognosy and Phytochemistry, 1(6), 168(2013).

18. M. Moniruzzaman, M.I. Khalil, S.A. Sulaiman, and S. H. Gan, African Journal of Traditional, Complementary, and Alternative Medicines, 9(1), 36(2012), DOI: 10.4314/ajtcam.v9i1.5.

19. M. O'Sullivan, Y.C. O'Callaghan, T.P. O'Connor, and N.M. O'Brien, Polish Journal of Food and Nutrition Sciences, 63(3), 167(2013), DOI: 10.2478/v10222-012-0080-6.

20. S. Sangsrichan, and W. Wanson, King Mongkut's Institute of Technology Ladkrabang Science Journal, 8, 1(2008).

21. C.E. Adeeyinwo, N.N.Okorie, and G.O.Idowu, International Journal of Science and Technology, 2(3), 247(2013).

22. D. Ahmed, M.M. Khan, and R. Saeed, Antioxidants, 4, 394(2015), DOI: 10.3390/antiox4020394.

23. M. Jun, H.Y.Fu, J.Hong, X. Wan, C.S. Yang and C.T. Ho, Journal of Food Science, 68, 2117(2003), DOI: 10.1111/j.1365-2621.2003.tb07029.x.

24. R.J. Wright, K.S. Lee, H.I. Hyacinth, J.M. Hibbert, M.E. Reid, A.O. Wheatley, and H.N. Asemota, Plants, 6(48), 1(2017), DOI: 10.3390/plants6040048.

25. C. Henríquez, S.Almonacid, I.Chiffelle, T. Valenzuela, M. Araya, L.Cabezas, R. Simpson, and H. Speisky, Chilean Journal of Agricultural Research, 70(4), 523(2010).

26. A. Blainski, G.C. Lopes, and J.C.P. de Mello, Molecules, 18, 6852(2013), DOI: 10.3390/molecules18066852.

27. B. Parikh, and V.H. Patel, Food Science and Human Wellness, 6(1), 10(2017), DOI: 10.1016/j.fshw.2016.11.002.

28. S. Lallianrawna, R.Muthukumaran, V. Ralte, G.Gurusubramanian, and N.S. Kumar, Science Vision, 13(4), 149(2013).

29. J.D. Everette, Q.M. Bryant, A.M. Green, Y.A. Abbey, G.W.Wangila, and R.B. Walker, Journal of Agricultural and Food Chemistry, 58(14), 8139(2010), DOI: 10.1021/jf1005935.

30. A. Altemimi, N.Lakhssassi, A.Baharlouei, D.G. Watson, and D.A. Lightfoot, Plants, 6(42), 1(2017), DOI: 10.3390/plants6040042.

31. X. Li, X. Wu, and L. Huang, Molecules, 14, 5349(2009), DOI: 10.3390/molecules14125349.

32. T.S. Teixeira, R.C. Vale, R.R. Almeida, T.P.S. Ferreira, L.G.L.Guimarães, Revista Virtual de Quimica, 9(4), 1546(2017), DOI: 10.21577/1984-6835.20170090.

[RJC-4018/2018] 